\title{
The simulation of the buoy for oscillating wave energy converter with Flow 3D
}

\author{
Zhu Jinghai $^{1, a}$, Feng Xuejiao, ${ }^{1, a}$, Fu Jinxiang ${ }^{1, a}$, He Xiang $^{1, a}$ \\ ${ }^{1}$ School of Environmental Science and Engineering, Shenyang Jianzhu University,China,110168 \\ a email:1611916143@qq.com
}

Keywords: Flow 3D;Buoy;Motion Response; Wave Energy; Donggang;

\begin{abstract}
In order to ensure energy collecting efficiency of oscillating wave energy converter in the actual application of Donggang's sea area in China, Flow 3D software is used to simulate hydrodynamic performance of different shape of the buoy. The result is : The average mass center $\mathrm{z}$ coordinates of the butterfly cylinder is higher than the hollow cylinder and vertical cylinder. So is the vibration velocity. The result shows that: The motion response of the butterfly cylinder is better than the hollow cylinder and the vertical cylinder. So the butterfly cylinder is more appropriate to be used in Donggang sea area. This can be an important reference for the application of the buoy in Donggang sea area.
\end{abstract}

\section{Introduction}

It has been a trend to promote renewable and clean energy in the days of increasingly serious environment pollution. As the most widely distributed renewable and clean energy, wave energy has been paid more and more attention. At present, many countries around the world has been close to or achieve the goal that wave energy power device can generate power in large scale ,with the electricity entering into the power grid. For example ,there are oscillating wave energy generator[1] in Sweden, English Pelamis device [2]located in Portugal and Wavestar device [3]in Denmark etc. Due to the limited ocean wave energy resources in China, there are two trends of the wave energy research currently :One is the study of single wave energy device, the other is an initial discussion on the industrialization of wave energy generating device. In this paper ,we do the simulation to analyze the motion responses of different shape of the buoy with the help of Flow 3D.Based on the actual condition of Donggang sea area, the best shape of buoy should be settled with analyzing the results of the simulation[4-5].

\section{Actual sea conditions}

Tab.1 Parameter table of the actual sea state[6-7]

\begin{tabular}{ccccccccc}
\hline \multirow{2}{*}{ sea } & \multicolumn{2}{c}{ Spring } & \multicolumn{2}{c}{ Summer } & \multicolumn{2}{c}{ Autumn } & \multicolumn{2}{c}{ Winter } \\
& height & period & height & period & height & period & height & period \\
\hline DongGang & $<1$ & $3 \sim 4.5$ & $<1.2$ & $4 \sim 5.5$ & $1 \sim 1.2$ & $5 \sim 5.5$ & $1.2 \sim 1.6$ & $5 \sim 6$ \\
\hline
\end{tabular}

Donggang, located in the Liaodong Peninsula, is shown in figure 1, which is adjacent to the Yalu River estuary, where the sea is at the northern end of the Yellow Sea. The effective wave height of this region is $1.25 \mathrm{~m}$, and the average period is $4.25-5.38 \mathrm{~s}$ [8-9]. The weather climate is a warm and monsoon climate, and the annual average temperature is about 9.5 degree. The area belongs to the regular semidiurnal tide with the tide range about $4.07 \mathrm{~m}$, and the strength of tide is medium strong[10].According to records, the sea ice phenomenon has appeared in the yellow sea river in 2008 and 2009,but the degree of it is less severe with certain effect on shipping and ports[11-12]. 


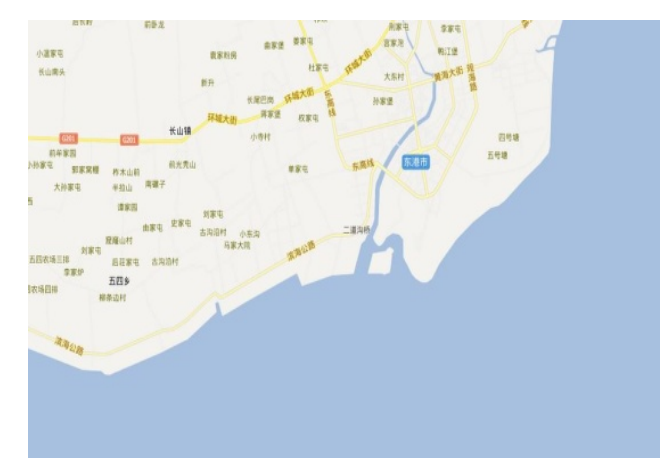

Fig.1 The location map of Dandong area

\section{Model simulation and analysis method}

Flow 3D is a kind of software that has been used in a lot of areas[13-14]. In this paper, a numerical tank is set up to give a simulation of different shape of the buoy. Three kind of shape of the buoy is selected based on the regulation of the buoy size setting[15].

Model Establishment

We established a work space in which the numerical tank is set up, according to the theory principle[16].And the size of the tank is $30 \mathrm{~m} \times 20 \mathrm{~m} \times 30 \mathrm{~m}$. The boundary of the tank is set up as follows.

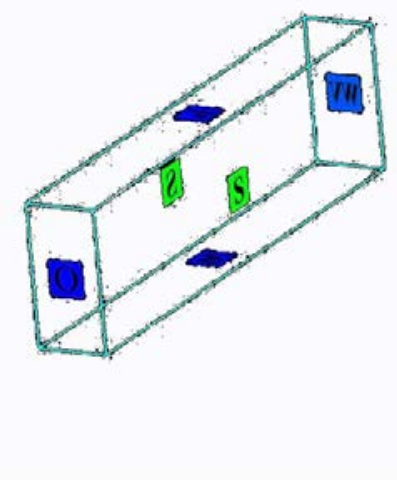

Fig.2 The boundary condition of the tank

In the numerical tank, WV is the wave generation boundary. This boundary provide us with 5 kind of wave, and one of them is chosen called stokes wave. And the height of the wave is $1.25 \mathrm{~m}$ based on the actual condition of Dong gang sea area. The period of wave is $4.25 \mathrm{~s}$, and the depth of the flow is $12 \mathrm{~m}$. The left side of the tank is outflow boundary, the bottom of the tank is the wall boundary , and the boundary layer before and after is the symmetry boundary. The depth of the flow is $12 \mathrm{~m}$, and after meshing.

We choose all physics model that is needed. The gravity and non-inertial reference frame is used. In the activate gravity, we set -9.8 in $\mathrm{Z}$ component. And in the model of moving and simple deforming objects, we use implicit mode to analyze the buoy. And the third model is viscosity and turbulence. We use RNG model to analyze the motion response of different shape of the buoy. The initial time step is set as $0.01 \mathrm{~s}$, restart data interval is $1 \mathrm{~s}$, and the selected data interval is $0.5 \mathrm{~s}$. And we also choose the output data of the simulation.

\section{Dimension setting analysis}

The movement energy of oscillating wave energy converter is mainly collected in the vertical direction, so we only consider the hydrodynamic analysis result in Direction $\mathrm{Z}$ in the modeling. The dimensions and shape of the model are set as follows:

The first shape of the buoy is vertical cylinder. The size of the cylinder is $1.3 \mathrm{~m}$ long for radius 
and $0.3 \mathrm{~m}$ long for column length. And the second shape of the buoy is butterfly cylinder with the size of $1.3 \mathrm{~m}$ long for outer ring, $0.78 \mathrm{~m}$ for inner ring, $0.3 \mathrm{~m}$ long for column length. And the third shape of the buoy is hollow cylinder. The size of it is $1.3 \mathrm{~m}$ long for outer ring diameter, $0.78 \mathrm{~m}$ long for inner ring diameter and $0.3 \mathrm{~m}$ long for column length.

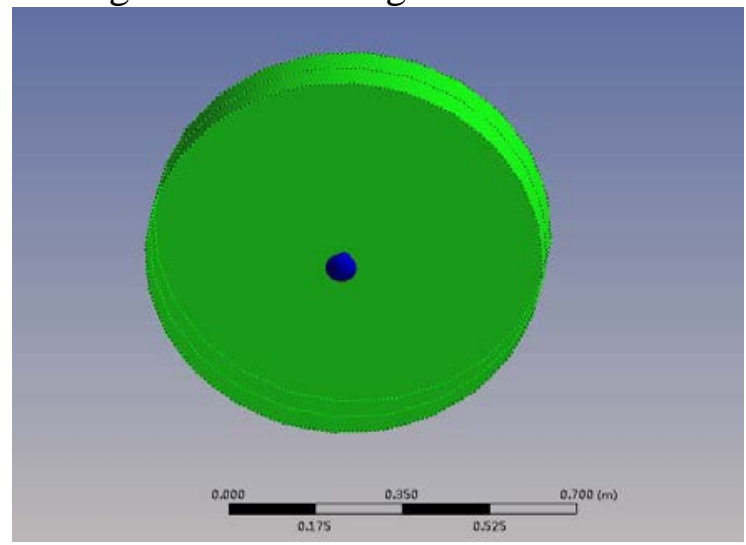

Fig.3 Vertical Cylinder

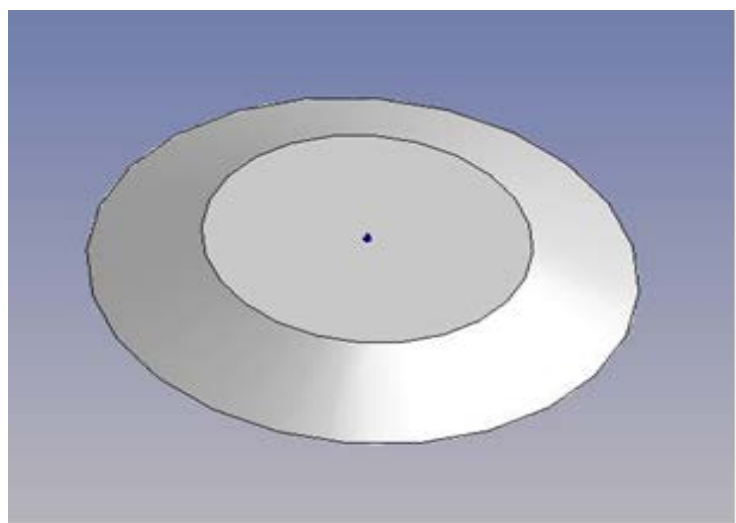

Fig.4 Butterfly Cylinder

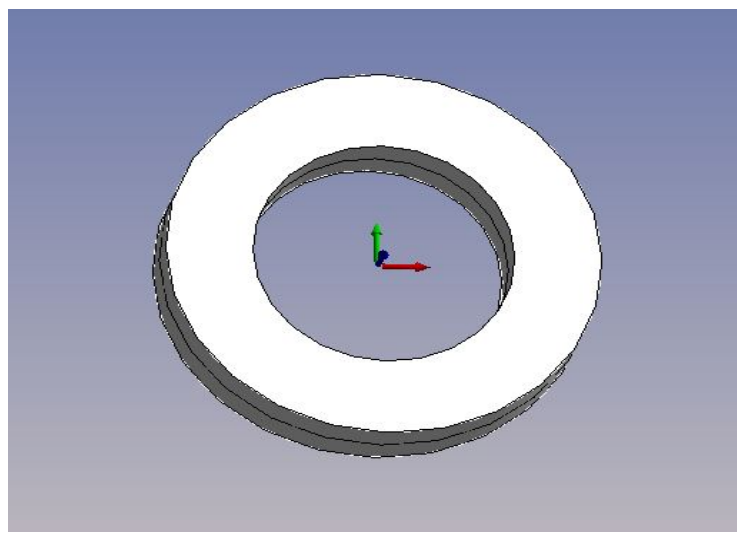

Fig.5 Hollow CylinderAnalysis and results 


\section{Analysis and results}

\section{Mass center $\mathrm{z}$ coordinates analysis}

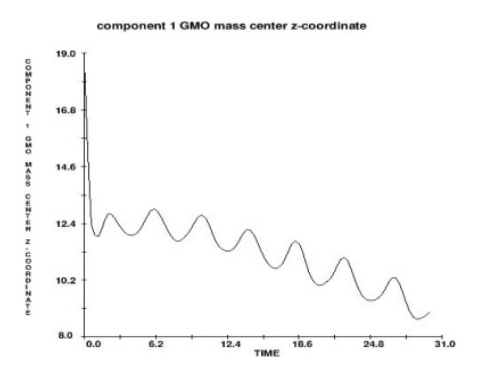

Fig.6 Vertical Cylinder z Coordinates

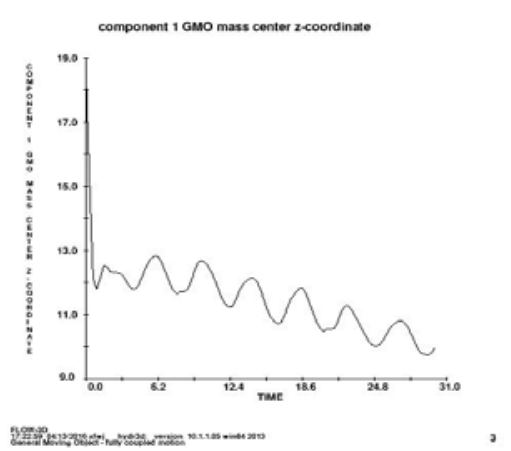

Fig.7 Hollow Cylinder z Coordinates

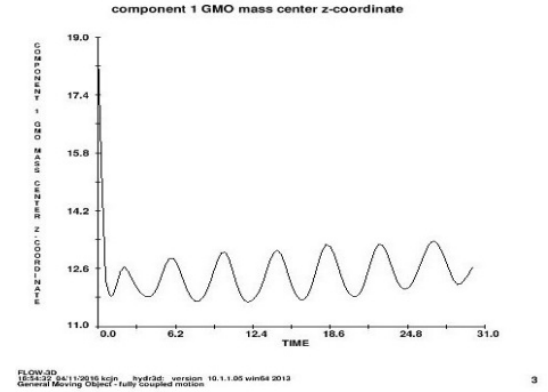

Fig.8 Butterfly Cylinder z Coordinates

Mass center $\mathrm{z}$ coordinates represents the position of the buoy in $\mathrm{Z}$ direction which include the water depth. With the statistics getting above, it can be easily seen that the stability of the vertical cylinder and hollow cylinder is lower than the butterfly cylinder. The highest point of mass center butterfly cylinder is 13.6,compared with vertical cylinder for $12.6 \mathrm{~m}$ and hollow cylinder for $13.1 \mathrm{~m}$.It can be seen that the butterfly cylinder holds much more potential compared with the other two. And the average mass center $\mathrm{z}$ coordinates of butterfly cylinder is $12.3 \mathrm{~m}$,higher than the hollow cylinder for 12.0 and vertical cylinder for $11.9 \mathrm{~m}$.So considering the aspect of motion position of the buoy, the butterfly cylinder is obviously better than the other two.

\section{Velocity in $\mathrm{Z}$ direction analysis}

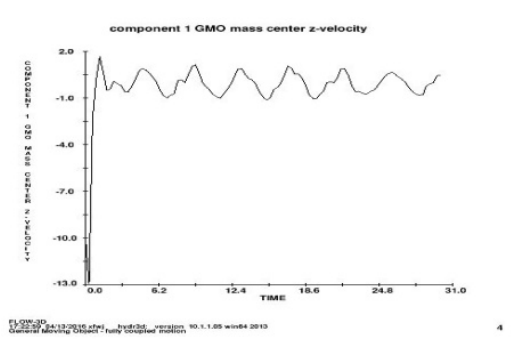

Fig.9Vertical Cylinder Velocity

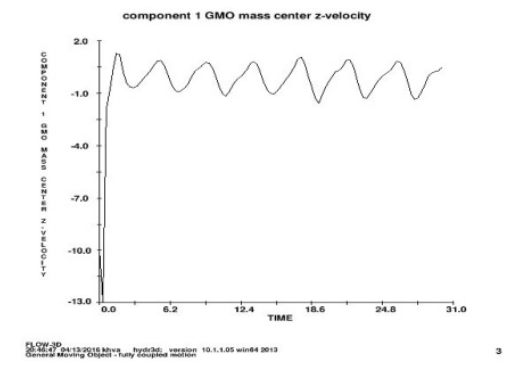

Fig.10 Hollow Cylinder Velocity

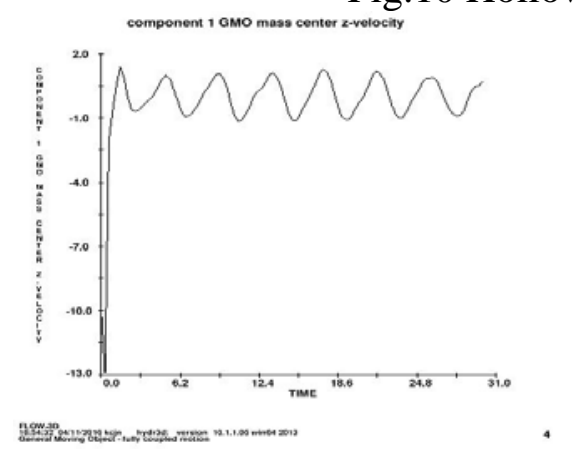

Fig.11 Butterfly Cylinder Velocity

The velocity of the buoy represents one of the motion response characteristics. From above, we can see that the range of velocity for different shape of the buoy is nearly the same, all of which are 
from $-1.0 \mathrm{~m} / \mathrm{s}$ to $2 \mathrm{~m} / \mathrm{s}$. But the hollow cylinder's changing frequency is a little different from the other two. Among three buoys, the butterfly cylinder holds the potential to change quicker. This statistics indicate that the vibration of the buoy is stronger than the other two.

\section{Conclusions}

With the use of Flow 3D , a numerical tank is set up to give a simulation of three different buoys based on the actual condition of the Dong gang sea. The result of the simulation shows that the average mass center $\mathrm{z}$ coordinates of the butterfly cylinder is higher than the other two. So is the vibration velocity. From the results, it can be known that the motion response of the butterfly cylinder is better than the hollow cylinder and the vertical cylinder. So the butterfly cylinder is more appropriate to be used in Donggang sea area.

\section{References}

[1]Erik Lejerskog, , Cecilia Boström, Ling Hai, Rafael Waters, Mats Leijon.Experimental results on power absorption from a wave energy converter at the Lysekil wave energy research site[J].Renewable energy 2015,05:9-14.

[2]Eugen Rusu, C. Guedes Soares.Coastal impact induced by a Pelamis wave farm operating in the Portuguese near shore [J].Renewable energy,2013,10:34-49.

[3]M. O'Connor, T. Lewis, G. Dalton,Techno-economic performance of the Pelamis P1 and Wavestar at different ratings and various locations in Europe[J].Renewable energy,2013,02:889-900.

[4]Shi Weiyong,Wang Chuankun,Shen Jiafa. China's marine energy resources and its prospects for development[J].Solar energy, 2011,06:913-923.

[5]You Yage,Li Wei,Liu Weimin,Li Xiaoying,Wu Feng. Development status and prospect of ocean energy power generation technology[J]. Automation of electric power system, ,2010,14:1-12.

[6]Wang Lvqing,Feng Weibing,Tang Youning. Wave energy characteristics of China's coastal provinces[J].Renewable energy, 2013,11:126-131.

[7]Li Yan,Bo Zhaohai. Experiment on the simulation ability of SWAN model in Bohai sea area[J].Ocean forecast,2005,03:75-82.

[8]Wang Guan,Zheng Chongwei,Li Sixiang,Qiu Xiaoqing. Analysis of wave characteristics in the northern part of the Yellow and Bohai sea[J]. China science and technology information,2011,22:36.

[9]Cheng Yijie. Basic characteristics of hydrological elements in the northern waters of Bohai and the Yellow Sea[J].China science and technology information, ,2006,17:40-41.

[10]Shi Weiyong,Wang,Wang Chuankun,Shen Jiafa. China's marine energy resources and its prospects for development[J].Solar energy,2011,06:913-923.

[11]Zhang Xiaoxia, Classification and evaluation of the risk of marine disaster in Liaoning [D]. Dalian Maritime University,2013.

[12]Zhang Yan. Risk assessment of major marine disasters in coastal areas of Liaoning Province[D].Liaoning Normal University,2014.

[13]Li Chenglong.Study on water dynamics and structure optimization of multi floated energy collecting device[D].Jimei University,2014.

[14]Ma Zhe.Study on characteristics of oscillating wave energy converter buoy[D]. Oceanic university of China,2013. 
[15] J. Falness, "A review of wave-energy extraction," Marine Structures,2007(20):185-201.

[16] Clement A. et al.Wave energy in Europe: current status and perspectives. Renewable and Sustainable Energy Reviews,2002. 